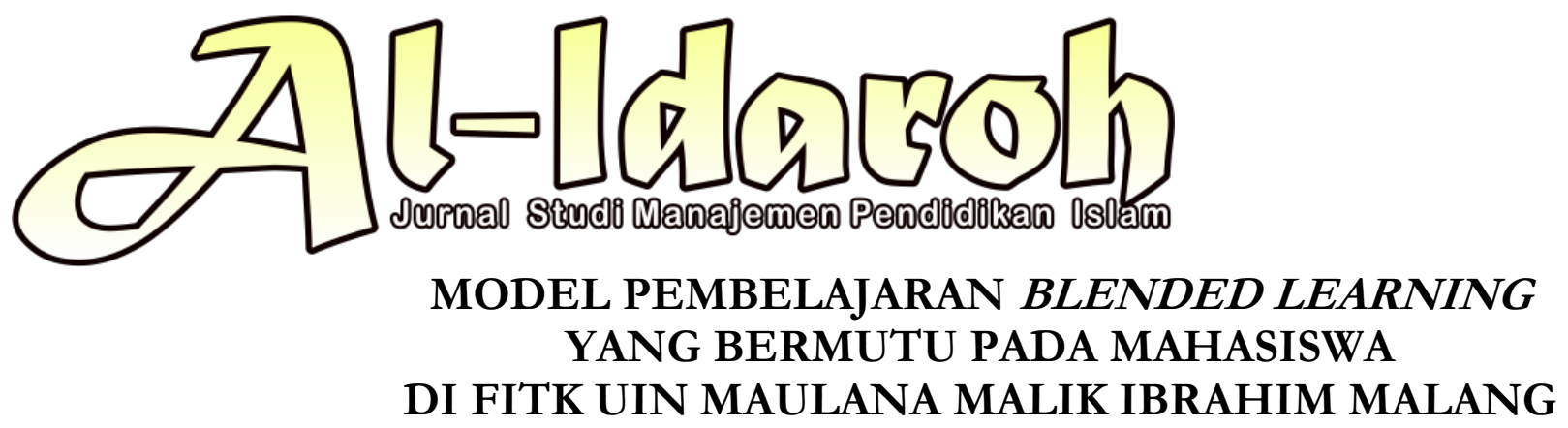

Muh. Hambali

FITK UIN Maulana Malik Ibrahim Malang

Email: hambali@pai.uin-malang.ac.id

\begin{abstract}
The industrial revolution is all life activies using teknology, including in educational institutions that have to improvise learning model. Learning is a process of imitating the example of educators in teaching students' knowledge, attitudes and skills. Lecturers are educators who have the authority to change the way of thinking and how to act towards the development of superior character, so lecturers need competency in the learning model. The learning model requires direct interaction so that the process of seeding values, culture and language manners occurs correctly. This model can be called an offline-based learning process. Offline learning has limited access to reference sources from websites and learning requires face-to-face learning. The referral source facilities available in the campus library are limited, while the onlinebased referral resource facilities are provided by UIN Maulana Malik Ibrabim Malang. This learning model provides global and fast access while learning and searching for various reference sources. The learning model is blended learning. Blended learning is mixed learning that combines conventional, face-to-face learning models with remote learning using internet networks. Lecturers use an offline process in the form of face to face at the beginning of the lecture to explain the learning scenario. After that, learning uses the e-learning website facility that is owned by UIN Maulana Malik Ibrabim Malang. This research approach uses qualitative, the type of research is a case study. This research will work to find facts on how the implementation of learning activities through blended learning at UIN Maulana Malik Ibrabim Malang. The findings show that the blended learning model is implemented by developing a combination of conventional approaches, namely face-toface learning using website-based learning, e-learning at UIN Maulana Malik Ibrabim Malang, which then succeeded in improving the quality of student learning.
\end{abstract}

Keywords: Blended learning, Website e-learning, Quality of learning

\title{
Pendahuluan
}

Zaman revolusi industri 4.0 yang ditandai dengan sistem cyber-physical. Dunia industri mulai menyentuh dunia virtual, berbentuk jejaring manusia, mesin, dan data yang lebih dikenal dengan nama Internet of Things (IoT). Perkembangan dunia kini, kian tidak berdaya menghindari implikasi revolusi industri 4.0 telah mengubah cara berpikir dan bertindak melalui komputerisasi dan digitalisasi. Artinya, dunia pendidikan tidak boleh merasa terasing dengan kemajuan teknologi saat ini. Dunia 


\section{Model Pembelajaran Blended Learning Yang Bermutu Pada Mahasiswa di FITK UIN Maulana Malik Ibrahim Malang}

pendidikan perlu merespon teknologi informasi berupa komputer atau smart phone yang terkoneksi dengan internet, Fasilitas ini hampir tersedia di setiap institusi pendidikan. Pendidikan 4.0 menggambarkan beragam cara dalam mengintegrasikan teknologi cyber, baik secara fisik maupun tidak, ke dalam dunia pembelajaran. ${ }^{1}$ Konsep ini juga merupakan lompatan dari pendidikan 3.0 yang lebih mencakup pertemuan ilmu saraf, psikolofi kognitif, dan teknologi pendidikan menggunakan teknologi digital dan mobile berbasis web.

Era revolusi industri 4.0, secara kusus pembelajaran yang visioner agar dapat menyiapkan generasi kreatif, kompetitif dan berdampak ke daya tahan dan daya juang. Hal tersebut salah satunya dapat dicapai dengan cara mengoptimalisasi penggunaan teknologi menjadi salah satu yang mampu menghasilkan output yang dapat mengikuti atau mengubah zaman menjadi lebih baik. Lembaga pendidikan perlu menanamakan karakter berprestasi yang dapat merespon lompatan-lompatan inovasi teknologi informasi dan teknologi pembelajaran.

Menurut Syamsul Arifin, ${ }^{2}$ pendidikan tak pelak rentan juga dengan disrupsi. Disrupsi seperti yang ditulis Rhenald Kasali (2017) adalah membuat hal baru sehingga yang lama ketinggalan zaman. Pendidikan akan tertinggal jika hanya mengulang hal lama dengan sedikit perbaikan (iterasi) dan tidak mau melakukan disruptive innovation. Era ini telah mengubah cara masyarakat bertranportasi setelah perlahan rintisan, seperti Uber, Grab dan Gojek mendisrupsi teknologi lama. Pelanpelan ini akan mengubah gaya hidup, yang semula mementingkan kepemilikan alat transportasi, lalu lebih mementingkan akses dan kecepatan. Hal ini melanda dunia pendidikan, proses pembelajaran mulai beralih dari luring ke daring. Revolusi industri ini tidak hanya menyasar dunia pertanian, perdagangan, dan industri, tetapi pengaruhya juga menyasar ke dalam dunia pendidikan dengan mulai digunakannya platform atau aplikasi-aplikasi komputer yang bersumber dari internet. ${ }^{3}$ Beberapa dosen mulai akrab saat pembelajaran di kelas dengan terhubung internet. Mereka lebih menyukai akses ilmu pengethuan yang bersumber dari internet.

\footnotetext{
${ }^{1}$ Sigit Priatmoko, Memperkuat Eksistensi Pendidikan Islam di Era 4.0. Ta'lim: Jurnal Studi Pendidikan Islam, Volume 1, Nomor 2 (2018), 2-3

2 Syamsul Arifin, Gangguan disrupsi, Republika, Selasa 12 Maret 2019

${ }^{3}$ Muh. Hambali dan Mu'alimin, Manajemen Pendidikan Islam Kontemporer, (Yogyakarta: IRCISod, 2020), 294
} 
Era ini juga, masyarakat memiliki kebebasan untuk memilih berbagai tawaran pelayanan yang memberi kemudahan serta kecepatan dalam segala pelayanan yang dibutuhkan ${ }^{4}$.Menurut Agus Nurjaman, era disrupsi yang melanda dunia pendidikan mengharuskan para dosen untuk melek teknologi. Berbagai keterampilan dalam pengoperasian teknologi, kususnya teknologi IT, harus benar-benar dikuasai oleh para dosen agar mereka tidak ketinggalan berbagai informasi penting yang dapat menunjang tercapainya tujuan pendidikan. ${ }^{5}$ Tujuan pendidikan akan tercapainya karakter yang unggul, maka membutuhkan pembelajaran yang tidak hanya pendekatan konvensional, tatap muka searah maupun hapalan. Proses pembelajaran adakecenderungan mengutamakan hapalan atau sekadar menemukan satu jawaban benar atau salah dari soal ujian. Di antaranya juga terlihat dalam kognisi civitas akademik PTKIN, tidak terekecuali di Universitas Islam Negeri Maulana Malik Ibrahim Malang yang memperlihatkan beragam aktifitas belajar mahasiswanya belum menunjukan keunggulan secara signifikanmeskipun fasilitas ditunjang infrastruktur Information Technology (IT) memadai. Sebagian dosen juga masih dominan dalam melaksanakan tugas pembelajaran yang bersifat konvensional. Pembelajaran menempatkan dosen sebagai satu-satunya sumber pengetahuan sehingga tidak mampu menanamkan nilai-nilai yang berdedikasi tinggi bagi pembentukan karakter mahasiswa. Sejatinya, proses belajar mengajar tidak harus tatap muka di kelas, tetapi dapat dilaksanakan secara virtual. Pembelajaran virtual dimaksudkan aktivitas belajar mengajar dari dosen dan mahasiswa berlangsug di dunia maya. Pembelajarannya menggunakan fasilitas cyberspace melalui koneksi internet.

Pembelajaran virtual yang menggunakan cyberspace yang terkoneksi internet. Caranya adalah dosen maupun mahasiswa menggunakan media laptop, notebook ataupun HP android. Media tersebut merupakan alat pembelajaran. Kususnya, UIN Maulana Malik Ibrahim Malang menggunakan cyberspace, yaitu menggunakan platform e-learning. Pembelajaran ini mengalami model perkembangan dari waktu ke waktu. Seiring bergulinnya dunia digital yang menyasar lembaga pendidikan, model

\footnotetext{
${ }^{4}$ Veronika Kusdiartini, Mengembangkan Sumber Daya Manusia yang Berkualitas di Era Disrupsi, dalam Benny Danang Setiaanto (ed), Unika dalam Wacana Publik: Transformasi Inspiratif (Tanpa Kota: SCU Knowledge Media, 2017), 17

5 Agus Nurjaman, Guru Figur Sentral dalam pendidikan: Menanam Sejuta Amal, Menabur Seribu Kebaikan (Tanpa Kota: Guepedia Indonesia, 2018), 88
} 


\section{Model Pembelajaran Blended Learning Yang Bermutu Pada Mahasiswa di FITK UIN Maulana Malik Ibrahim Malang}

pembelajaran yang lebih banyak memanfaatkan internet sebagai sumber dan media belajar ini menawarkan berbagai banyak kemudahan. Namun, pengembangan teknologi untuk pendidikan itu tidak hanya memberikan dampak positif bagi lembaga pendidikan, melainkan juga ada dampak negatifnya.

Perkembangan mahasiswa saat ini, terlihat masih memposisikan fasilitas yang tersedia di kampus sekedar ajang media sosial, belum dapat menjadi sarana menunjang pembelajaran yang bermakna. Sistem pembelajaran membutuhkan adaptasi kurikulum, kemampuan mahasiswa menggunakan Information Technology (IT), Operational Technology (OT), Internet of Things (IoT), dan Big Data Analitic, mengintegrasikan objek fisik, digital dan manusia sehingga mahasiswanya kompetitif dan terampil terutama dalam aspek data literacy, technological literacy and human literacy. Agar pembelajaran berbasis cyberspace, sudah seharusnya dilakukan pengelolaan terhadap model pembelajaran berbasis platform, yaitu elearning yang terus-menerus dilakukan inovasi. Salah satu pertimbangan keberhasilan mempunyai platform model pembelajaran, juga perguruan tinggiini, UIN Maulana Malik Ibrahim Malang sebagai kampus Ulul-Albab sebagai pelopor PTKIN yang telah mempunyai standar pengelolaan kelembagaan BLU meraih peringkat satu (1) kampus dengan pengelolaan keuangan badan layanan umum 2016-2017 tingkat nasional. Menteri Agama, Lukman Hakim Saifuddin pun memberi penghargaan kepada UIN Maulana Malik Ibrahim Malang yang diterima langsung oleh rektor. Penghargaan diberikan usai Rapat Koordinasi Kuasa Pengguna Anggaran (KPA) Kementerian Agama Republik Indonesia 2018, di Jakarta 7 Agustus 2018.

Aspek kelembagaan mempunyai kemauan pengelolaan pembelajaran. Model pembelajaran yang mengintegrasikan metode konvensional dengan TIK (Teknologi Informasi dan Komunikasi) untuk inovasi mutu belajar mahasiswa adalah menggunakanpembelajaran bauran (Blended Learning). Melalui model belajar semacam ini, dosen mempunyai kesempatan menanamkan nilai-nilai kedisiplinan akademik dan ketaatan menjalankan agama lebih bermakna kepada mahasiswa dan mahasiswa memiliki kebebasan mengembangkanmateri yang harus dipelajarinya terlebih dulu di setiap satuan kegiatan perkuliahan yang telah ditetapkan, bahkan waktu harus dimulai dan diakhiri kegiatan belajarnya. Selebihnya, sekalipun telah mengulangi beberapa kali dalam belajaranya namun memahami materi perkuliahanya, mahasiswa dapat 
menghubungi dosen pengampu matakuliahnya melalui email, chat atau mengikuti dialog interaktif secara on line, termasuk membaca hasil diskusi di message board yang tersedia di LMS (Learning Management System).

Kemanfaatan yang lebih tentu kian nyata dirasakan mahasiswa dalam belajarnya setelah blended learning memberi kemudahan mengkombinasikan berbagai strategi penyampaian materi, gaya pembelajaran dan memperkenalkan berbagai pilihan media dialog antara dosen dengan mahasiswa. Lebih dari itu, kombinasi pengajaran langsung (face-to-face) dan pengajaran online model Blended learning menjadi elemen interaksi sosial yang unik yang secara keseluruhan kelebihan model pembelajaran ini malampaui e-learning. Kegiatan belajar mengoptimalkan model Blended learning diperguruan tinggi dengan segala keunggulan dan efektifitasnya, tentu memerlukan kerja akademik untuk mendalami dan mengembangkannya. Penelitian ini akan bekerja dengan mengangkat judul Model Pembelajaran Blended Learning yangBermutu pada Mahasiswa di FITK Universitas Islam Negeri Maulana Malik Ibrahim Malang. Selanjutnya, penelitian ini menempatkan fokus penelitian, model pembelajaran Blended Learning di UIN Maulana Malik Ibrahim Malang, kususnya Jurusan Pendidikan Agama Islam Fakultas Ilmu Tarbiyah dan Keguruan (FITK) agar tujuan untuk mengetahui model pembelajaran blended learning yang dapat menanamkan pengetahuan, sikap dan keterampilan secara bermutu kepada mahasiswa.

\section{Metode Penelitian}

Penelitian ini menggunakan pendekatan kualitatif. Penelitian kualitatif merupakan suatu penelitian yang ditujukan untuk mendeskripsikan dan menganalisis fenomena, peristiwa, aktivitas, sosial, sikap, kepercayaan, persepsi, pemikiran orang secara individu maupun kelompok. ${ }^{7}$ Peneliti berusaha mengungkap fenomena pengembangan kompetensi guru untuk meningkatkan mutu pendidikan di sekolah secara alamiah dan kehadiran peneliti tidak menganggu dan mempengaruhi dinamika yang terjadi di kampus UIN Maulana Malik Ibrahim Malang, kususnya FITK.

Jenis penelitian yang digunakan dalam penelitian ini adalah penelitian deskriptif. Penelitian deskriptif merupakan penelitian yang berusaha mendeskripsikan

${ }^{6}$ Husamah, Pembelajaran Bauran (Blended Learning) (Jakarta: Prestasi Pustaka, 2014), 22

${ }^{7}$ Nana Syaodah Sukamdinata, Metode Penelitian Pendidikan (Bandung: Remaja Rosdakarya, 2008), 60 


\section{Model Pembelajaran Blended Learning Yang Bermutu Pada Mahasiswa di FITK UIN Maulana Malik Ibrahim Malang}

dan menginterpretasikan data yang ada, di samping itu penelitian ataupun peristiwa sebagaimana adanya, sehingga bersifat sekedar mengungkapkan deskriptif terbatas pada usaha mengungkapkan suatu masalah atau dalam keadaan fakta (fact finding). ${ }^{8}$ Maka peneliti dalam melakukan penelitian ini akan membahas dan mendeskripsikan mengenai tentang cara-cara pembelajaran blanded learning dilaksanakan di FITK UIN Maulana Malik Ibrahim Malang.Melakukan pengumpulan data pelaksanaan pembelajaran Blanded Learning sebagai landasan teoritis. a). Melakukan pengumpulan Pengembangan Blanded Learning di UIN Maulana Malik Ibrahim Malang, b). Melakukan analisis untuk mendapat abstraksi tentang pengembangan Model Pembelajaran Blanded Learning di UIN Maulana Malik Ibrahim Malang

\section{Hasil dan Pembahasan}

Blended Learning mulanya digunakan untuk menggambarkan percobaan mata kuliah yang menggabungkan tatap muka, luring dengan daring sebagai model pembelajarannya secara sederhana, yang kemudian popularitasnya lebih akrab dikenal sebagai pengkombinasian dari banyak model pembelajaran seperti tatap muka, pembelajaran berbasis computer (offline), dan komputer secara online (internet dan mobile learning). Pembelajaran ini menggabungkan tatap muka dan online learning. Pembelajaran ini juga, gabungan dua unsur utama, yakni pembelajaran di kelas dengan tatap muka dengan pembelajaran seacar online. Gabungan tersebut biasa disebut dengan blended learning (pembelajaran campuran). Salah satu tipe yang dapat digunakan yaitu tipe online - tatap muka - online. Untuk melaksanakan pembelajaran secara blended, diperlukan suatu aplikasi yaitu learning management system (LMS). Learning Management System (LMS) merupakan suatu aplikasi atau software yang digunakan untuk mengelola pembelajaran online yang meliputi beberapa aspek yaitu materi, penempatan, pengelolaan, dan penilaian (Mahnegar, 2012). ${ }^{9}$

Salah satu syarat penggunaan LMS dalam proses pembelajaran, dosen dan mahasiswa terhubung jaringan internet. LMS memiliki beberapa fitur yang

\footnotetext{
${ }^{8}$ Hadari Nawawi, Metodologi Penelitian Bidang Sosial (Yogyakarta: Gajah Mada Press, 2019), 31

${ }^{9}$ Winda Wijayanti dkk, Pengembangan Perangkat Blended Learning Berbasis Learning Management System pada Materi Listrik Dinamis, Jurnal ilmiah Pendidikan Fisika AL-BiRuNi, 06 (1) (April 2017), 1-12 http://repository.lppm.unila.ac.id/6231/1/2017
} 
mendukung proses pembelajaran online, misalnya forum diskusi, kurikulum sumber pembelajaran, kehadiran, kuis, tugas, jenis informasi akademik, dan pengelolaan data mahasiswa. Penelitian dari Bibi menunjukan bahwa terdapat peningkatan pemahaman peserta didik yang menggunakan pembelajaran berbasis blended learning bila dibandingkan pembelajaran konvensional ${ }^{10}$. Pelaksanaan pembelajaran blended learning bersifat saling melengkapi antara pembelajaran tatap muka dengan pembelajaran e-learning. Berdasarkan beberapa penelitian terdahulu menunjukan bahwa pelaksanaan blended learning sebagai pelengkap materi pembelajaran, sebagai alat untuk meningkatkan kemadirian mahasiswa. Selain itu, blended learning mampu meningkatkan pengetahuan peserta didik serta respon mahasiswa.

Pembelajaran bauranmemiliki tujuan utama memberikan kesempatan bagi berbagai karakteristik peserta didik memiliki kemandirian dalam belajarnya secara sustainable, berkembang dan lebih menarik sehingga efektifitas maupun efisiensinya lebih nyata dirasakan. Dziuban, Hartman, dan Moskal(2004) dalam penelitianya membuktikan adanyapotensi untuk meningkatkanhasilbelajar siswa dan juga menurunkantingkatputus sekolahdibandingkandengan pembelajaran yangsepenuhnya pembelajaran on line. Pembelajaran berbasis blended learning, juga bermanfaatuntuk meningkatkan hubungan komunikasi pada tiga model pembelajaran yaitu lingkunganpembelajaran yang berbasis ruang kelas tradisional, yang blended, dan yang sepenuhnya online. Banyak peneliti membuktikanya, bahwa Blended Learningmenghasilkan perasaanberkomunitas lebih kuat antar mahasiswa daripada pembelajaran tradisional atau sepenuhnya online (Rovai dan Jordan, 2004).

Pembelajaran menggunakan pertemuan secara tatap muka dan pembelajaran secara online baik di dalam kelas maupun di luar kelas. Strategi pembelajaran yang akan digunakan yaitu pembelajaran berbasis masalah. Pemilihan strategi ini disesuaikan dengan hasil observasi yang menunjukan daya analisis peserta didik (mahasiswa) masih rendah sehingga perlu menggunakan strategi yang sesuai dengan

10 S. Bibi. Efektivitas Penerapan Blended Learning terhadap Tingkat Pemahaman Mahasiswa Mata Kuliah Algoritma dan Pemrograman Dasar. Jurnal Pendidikan Informatika dan Sains, (2015), 284 


\section{Model Pembelajaran Blended Learning Yang Bermutu Pada Mahasiswa di FITK UIN Maulana Malik Ibrahim Malang}

permasalahan tersebut. Pendidik akan memberikan materi pembelajaran dan tugas secara online kemudian akan diulas pada pembelajaran secara tatap muka di sekolah ${ }^{11}$.

Setelah menghimpun dan memetakan beragam data yang berhasil dikumpulkan, ditemukan bahwa pelaksanaan kegiatan pembelajaran di FITK UIN Maulana Malik Ibrahim Malang yang teridentifikasi menggunakan blended learning diantaranya adalah;website based learning, yaitu https://elearning.uin-malang.ac.id.Website based learningmenggunakane-learning yang dikembangkan untuk UIN Maulana Malik Ibrahim Malang menggunakan platform Moodle. Moodle merupakan salah satu platform Learning Management System(LMS) yang banyak di gunakan di berbagai lembaga pendidikan baik di tingkat nasional maupun internasional. Lisensi Moodle adalah gratis dan memiliki sumber terbuka (free\&open sources) sehingga dapat dengan bebas di kembangkan sesuai dengan kebutuhan lembaga yang menggunakan. Sistem Moodle yang telah digunakan adalah versi 3.6 dimana terdapat beberapa perubahan (penambahan fitur) dibandingkan dari versi-versi sebelumnya.

Hal ini merupakan ikhtiar lembaga untuk menyelenggarakan kegiatan pembelajaran dengan pemanfaatan internet untuk menunjang peningkatan mutu pembelajaran yang dilakukan di kelas. Sistem E-Learning UIN Maulana Malik Ibrahim telah terintegrasi dengan sistem SIAKAD sehingga plotting / penempatan kelas perkuliahan baik bagi dosen maupun mahasiswa dilakukan secara otomatis sesuai dengan data KRS yang ada di SIAKAD. User Course B Course C Course A Topics Activity Resources. Oleh karena itu username dan password yang digunakan untuk mengakses elearning juga sama dengan username \& password SIAKAD. Seorang dosen dapat mengajar di beberapa kelas begitu pula seorang mahasiswa dapat mengambil beberapa kelas perkuliahan. Maka ketika pengguna login di elearning akan ditampilkan semua kelas yang dapat diakses oleh pengguna (dosen / mahasiswa). Apabila dosen mengampu beberapa kelas yang sama (dengan materi yang sama), isi dari course / kelas perkuliahan dapat di copy \& paste ke kelas perkuliahan yang lain. Dalam Web Based Learning, dokumen matedi perkuliahan ini dikembangkan dalam format hypertext dengan menggunakan Hypertex Markup Language (HTML).

${ }^{11}$ Nur Aeni, Titi Prihatin \& Yuli Utanto, Pengembangan Model Blended Learning Berbasis Masalah pada Mata Pelajaran Sistem Komputer, Innovative Journal of Curriculum and Educational Technology IJCET 6 (2) (2017) 
Kerangka konsepini menyebabkan terjadinya tautan dari suatu dokumen ke dokumen lain. Selain itu fasilitas ini bersifat multimedia, yang terdiri kombinasi unsur teks, foto, grafika, audio, animasi dan video. Dalam hal ini, dosen terampil dalam pencarian informasi di internet, membimbing pembelajaran yang bermutu kepada mahasiswa dalam menemukan situs-situs yang relevan dengan pembelajaran, menyajikan materi melalui website dan diminati, dan melayani bimbingan serta komunikasi melalui internet. Adapun fungsi dari internet dalam pembelajaran ini adalah untuk memberikan pengayaan dan komunikasi antara mahasiswa dan dosen, sesama mahasiswa, anggota kelompok, atau mahasis dengan narasumber.

Menurut Rusma ${ }^{12}$ bahwa website based learning merupakan proses pembelajaran menggunakan media website yang berbasis pada aktivitas membaca, berdiskusi, mengkontruksi pengetahuan serta pencarian informasi dan bisa diakses melalui internet. Pemanfaatan internet sebagai media pembelajaran mengkondisikan mahasiswa untuk belajar secara mandiri dan mahsiswa dapat mengakses secara online dari berbagai situs yang ada di dalam internet serta dapat menganalisis informasi yang relevan dengan materi. Adapun peran dosen adalah fasilitator agar semua kombinasi model pembelajaran dapat berjalan dengan optimal sehingga menjafi efektif.Model pembelajaran ini memberi penekanan pada pemberian materi perkuliahan melalui media internet yang dikonvergensi dengan kegiatan pembelajaran konvensional tatap muka. Seluruh materi perkuliahan telah disampaikan melalui website yang telah di buat Dosen, kemudian diberikan penguatan pada saat perkuliahan yang dilakukan secara tatap muka. Dengan demikian, keduanya memiliki fungsi saling melengkapi dan menguatkan.

Pada tahapan sebelum pelaksanaan e-learning di FITK UIN Maulana Malik Ibahim Malang, dimulai dengan perkenalan antara mahasiswa dengan dosen di kelas A dan B Jurusan PAI Semester I. Pada satu sesi di pertemuan pendahuluan yang dilakukan secara tatap muka di kelas selama lebih kurang 30 menit. Kemudian dijelaskan terlebih dahulu materi perkuliahan yang akan dilaksanakan bersama. Bersamaan dengan penjelasan materi perekuliahan tersebut diberikan motivasi, paradigma pembelajaran, kontrak belajar dan perkenalan materi adasar perkuliahan

${ }^{12 R u s m a n, ~ d k k, ~ 2012, ~ P e m b e l a j a r a n ~ B e r b a s i s ~ T e k n o l o g i ~ I n f o r m a s i ~ d a n ~ K o m u n i k a s i, ~(J a k a r t a, ~ R a j a w a l i ~ P e r s), ~}$ 263 


\section{Model Pembelajaran Blended Learning Yang Bermutu Pada Mahasiswa di FITK UIN Maulana Malik Ibrahim Malang}

agar mahasiswa lebih mempunyai kapasitas belajar dan pembelajaran lebih menarik. Pertemuan selebihnya dilalukan melalui laman website e-learning yang sudah tersedia di kampus UIN Maulana Malik Ibrahim Malang. Hal ini digunakan untuk pembelajaran dilengkapi dengan fitur file materi yang bisa didownload, link ke website terkait, forum dan chatting.

Salah satu metode pembelajaran yang bisa dilakukan melalui website ini adalah problem solving. Dosen memberikan permasalahan yang diposting di forum, kemudian mahasiswa secara berkelompok berupaya merumuskan solusi dari permasalahan tersebut dengan mempelajari file materi dan mengunjungi website terkait. Dengan memanfaatkan fitur forum dan chatting, mahasiswa dapat berdiskusi dan mengeluarkan pendapatnya sehingga tiap kelompok kemudian dapat membuat kesimpulan dari hasil diskusi yang mengarah pada solusi permasalahan.

Hasil diskusi mahasiswa pada forum di web, dievaluasi oleh dosen bersama dengan mahasiswa. Evaluasi ini dilakukan setelah tenggat waktu yang diberikan untuk diskusi berakhir. Evaluasi ini berkaitan dengan materi pembelajaran dan permasalahan mahasiswa saat menggunakan website. Evaluasi yang berkaitan dengan materi pembelajaran, mahasiswamemberikan tanggapan yang beragam. Seluruh kelompok mahasiswa dapat memberikan solusi permasalahan yang diposting di forum oleh dosen.

Sekalipun teknologi website memungkinkan pembelajaran dilakukan virtual penuh, namun kesempatan itu digunakan pengembangan pembelajaran setelah pembelajaran berbasis tatap muka di kelas. Interaksi satu sama lain untuk dapat membangun komunikasilebih bermakna. Ada tiga alasan mengapa forum tatap muka masih dibutuhkan dalam kegiatan pembelajaran ini. Alasan tersebut adalah:

1. Perlunya forum untuk menjelaskan maksud dan mekanisme belajar yang akan dilalui bersama secara langsung dengan semua mahasiswa. Keberhasilan sebuah proses pembelajaran juga ditentukan oleh pemahaman mahasiswa tentang apa, mengapa dan bagaimana proses belajar dan mengerjakan tugas berlangsung. Mahasiswa perlu mengetahui keluaran dan kompetensi apa yang akan didapat setelah mengikuti suatu kegiatan pembelajaran.

2. Perlunya memberikan pemahaman sekaligus pengalaman belajar dengan mengerjakan tugas secara kelompok dan kolaboratif pada setiap mahasiswa. 
Karena model pembelajaran yang dirancang menuntut kerja kelompok, maka mahasiswa perlu memiliki kompetensi da komunikasi. Iklim partisipatoris dan aktif terlibat dalam pelbagai kegiatan perlu dikenalkan sekaligus dialami oleh setiap mahasiswa. Untuk itu, mengenai pribadi satu dengan yang lain perlu dilakukan secara langsung guna membangun suatu kelompok yang kokoh, selama kerja secara virtual.

3. Perlunya pemberian pelatihan secukupnya dalam menggunakan komputer yang akan digunakan sebagai media komunikasi berbasis web kepada setiap mahasiswa. Dengan menyertakan berbagai kegiatan menggunakan komputer beserta fasilitas sistem komunikasi pendukungnya, maka setiap mahasiswa harus mempunyai keterampilan mengoperasikannya.

Ditemukan tujuh (7) dari enam belas (16) dosen yang melaksanakan blended learning di Jurusan Pendidikan Agama Islam (Strata-1) menerapkan jenis blended learning menurut Khan adalah kombinasi offlinedan onlineLearning ${ }^{13}$. Beberapa dosen hanya menyajikan blog untuk materi kuliah, blog untuk tugas, email untuk pengumuman, e-mailuntuk penugasan, dan menyelenggarakan presentasi dan diskusi di kelas, sedangkan hanya seorang dosen memadukannya dengan jenis blended learningyaitu kombinasi antara pembelajaran terstruktur dan tidak terstruktur. Dosen tersebut juga menyajikan pembelajaran terurut dan terencana, fleksibilitas urutan penyajian materi sesuai kebutuhan, penugasan terstruktur, dan memberikan kebebasan memilih tema penugasan, waktu penugasan, serta kinerja dan evaluasi.Implementasi pembelajaran bauran atau blended learning menjadi jalan keluar yang dianggaptepat atas berbagai kritik dan kekurangan e-learning dan kritik atas ketertinggaln pembelajarantatap muka. blended learning berarti penggabungan berbagai ciri keunggulanpembelajaran berbasis internet danpemanfaatan teknologi mobile dengan pembelajaran tatap muka guna meningkatan kompetensi, kreativitas dan daya inovasi mahasiswa serta menjadikanmahasiswa berkarakter.

Dalam kegiatan pembelajaran, blended learning memberi manfaat bagi kemudahan dosen maupun mahasiswa dalam proses belajar dan mengajar sehingga bisa berdiskusi tanpa tatap muka kapan saja dan dimana saja.

${ }^{13}$ Santi Maurdiati, Penerapan E-Learning di Perguruan Tinggi, Jurnal Perspektif Ilmu Pendidikan, Fakultas Ilmu Pendidikan Universitas Negeri Jakarta, Volume 32, No 1, 2018. 


\section{Model Pembelajaran Blended Learning Yang Bermutu Pada Mahasiswa di FITK UIN Maulana Malik Ibrahim Malang}

Pembelajaran ini tersedia untuk perangkat smartphone, android dan iphone. Pembelajaran ini tersedia kampus melalui layanan wifi yang dapat diakses di masingmasing kelas dengan menggunakan pasword yang dimiliki oleh setiap mahasiswa. Demikian juga, dosen dapat mengakses wifi kampus menggunakan pasword untuk melakaksanakan pembelajaran blended learning, Pembelajaran ini juga bisa diakses oleh orang tua mahasiswa. Sehingga orang tua dapat memantau anaknya dalam proses pembelajaran.

Dalam kegiatan pembelajaran, dosen di Jurusan Pendidikan Agama Islam (Strata-1) dapat mendesain aktivitas pembelajaran secara online. Sedikit dosen yang dapat memberikan kesempatan kepada mahasiswa untuk membaca, mengkaji, dan mempelajari literatur dengan cara searching sendiri dari internet menggunakan search engine (Google, Yahoodan lain-lain) dan mengunduh materi (dalam format ppt, pdf, html, video, dan lain-lain) yang sudah diunggah (upload), sedangkan untuk aktivitas menulis makalah individu, hasil resensi buku, dan refleksi topik-topik perkuliahan secara e-learning, sebagian dosen yang dapat memberikan kesempatan kepada mahasiswa untuk mengirim tulisan (makalah dan lain-lain) dengan cara submit langsung via fasilitas submit assignment yang ada.

Hasil pengamatan menunjukkan pada minggu ketiga dan keempat perkuliahan hanya 32\% mahasiswa yang berhasil mengunduh materi perkuliahan yang dikirimkan dosen dengan lancar, 32\% berhasil setelah melakukan kesalahan beberapa kali, sedangkan yang 36\% lainnnya tidak berhasil atau tidak bisa melakukannya. Kedua, berkaitan dengan aktivitas mengunduh/mengunggah tugas, 27\% mahasiswa yang sukses melakukannya tanpa kesulitan, 38\% berhasil meskipun masih ada kesalahan cara dan prosedur, sedangkan 35\% lainnya tidak berhasil melakukannya. Ketiga, seperti halnya indikator kedua, mahasiswa yang dapat memanfaatkan aplikasi LMS dengan baik untuk mengerjakan kuis ada 27\%, yang 38\% berhasil namun masih kesalahan, dan 35\% tidak dapat melakukaknya. Dengan demikian, mahasiswa yang belum berhasil mengoperasikan aplikasi LMS adalah (1) 38\% untuk mengunduh materi, (2) 35\% dalam mengunduh/mengunggah tugas, dan (3) $35 \%$ untuk mengerjakan kuis.

Berdasarkan capaian indikator tersebut, Peneliti bersama dosen pengampu matakuliah melakukan refleksi dengan mengidentifikasi sumber kesulitan 
pengoperasian e-learning.uin.malang.ac.id ini melalui wawancara terhadap mahasiswa yang masih bermasalah. Adapun penyebab masalah pada mahasiswa adalah (1) kurangnya penguasaan kosa kata berbahasa Inggris, (2) tidak memahami maksud ikon-ikon yang terdapat dalam website UIN, (3) tidak memahami fungsi fitur-fitur dalam aplikasi, dan (4) terbatasnya waktu pengerjaan/revisi tugas karena dosen terlambat dalam pengirimannya.

\section{Kesimpulan}

Model pembelajaran blended learning di UIN Maulana Malik Ibrahim Malang. Website Based Learningmenggunakan elearning.uin-malang.ac.id. Website ini mempunyai fitur khas pembelajaran dengan menggunakan website yang telah di buat oleh subyek maupuan obyek pendidikan dengan orientasi pada aktivitas membaca, berdiskusi, mengkonstruksi pengetahuan, ekspresi melalaui fitur chat, bahkan melakukan kegiatan pencarian informasi. Implementasi website based learning sebagai model blended learning di UIN Maulana Malik Ibrahim Malang. Dosen membuat website yang sudah di desain sedemikian sesui kebutuhan perkuliahan. Dosen memberikan pengarahan menganai materi perkuliahan. Mahasiswa merespon penjelasan dan arahan dosen dengan mempelajari materi perkuliahan di website. Mengevaluasi pelaksanaan perkuliahan yang diselenggarakan sesuai dengan kalender akademik, Efektifitas model pembelajaran blended learning melalui website blanded learning di UIN Maulana Malik Ibrahim Malang. Kekurangan dalam pelaksanaan pembelajaran menggunakan model website e-learning, diantaranya; akses untuk mengikuti pembelajaran dengan menggunakan web sering kali menjadi masalah bagi pembelajar. Kesulitan dalam pengiriman tugas, meliputi pengaturan batas waktu dan pemberian peringkat nilai. Kesulitan dalam pengadaan kuis terletak pada hal pengaturan, batas waktu dan penskoran. Kelebihan Model Pembelajaran website based learning, diantaranya; Dimungkinnya terjadinya distribusi pendekatan dan kapasitas daya tampung yang tidak terbatas karena tidak memerlukan ruang kelas. Proses pembelajaran tidak terbatas oleh waktu. 


\section{Model Pembelajaran Blended Learning Yang Bermutu Pada Mahasiswa di FITK UIN Maulana Malik Ibrahim Malang}

\section{Daftar Rujukan}

Arifin. Syamsul, Gangguan disrupsi, Republika, Selasa 12 Maret 2019

Hambali. Muh, dan Mu'alimin, Manajemen Pendidikan Islam Kontemporer, Yogyakarta: IRCISod, 2020.

Husamah, Pembelajaran Bauran (Blended Learning), Jakarta: Prestasi Pustaka, 2014.

Kusdiartini. Veronika, Mengembangkan Sumber Daya Manusia yang Berkualitas di Era Disrupsi, dalam Benny Danang Setiaanto (ed), Unika dalam Wacana Publik: Transformasi Inspiratif Tanpa Kota: SCU Knowledge Media, 2017.

Nawawi, Hadari, Metodologi Penelitian Bidang Sosial Yogyakarta: Gajah Mada Press, 2019.

Nur Aeni. Titi Prihatin, \& Utanto. Yuli, Pengembangan Model Blended Learning Berbasis Masalah pada Mata Pelajaran Sistem Komputer, Innovative Journal of Curriculum and Educational Technology IJCET 6 (2), 2017.

Nurjaman. Agus, Guru Figur Sentral dalam pendidikan: Menanam Sejuta Amal, Menabur Seribu Kebaikan, Tanpa Kota: Guepedia Indonesia, 2018.

Priatmoko. Sigit, Memperkuat Eksistensi Pendidikan Islam di Era 4.0. Ta'lim: Jurnal Studi Pendidikan Islam, Volume 1, Nomor 2, 2018.

Rusman, dkk, Pembelajaran Berbasis Teknologi Informasi dan Komunikasi, Jakarta, Rajawali Pers, 2012.

S. Bibi, Efektivitas Penerapan Blended Learning terhadap Tingkat Pemahaman Mahasiswa Mata Kuliah Algoritma dan Pemrograman Dasar. Jurnal Pendidikan Informatika dan Sains, 2015.

Santi Maurdiati, Penerapan E-Learning di Perguruan Tinggi, Jurnal Perspektif Ilmu Pendidikan, Fakultas Ilmu Pendidikan Universitas Negeri Jakarta, Volume 32, No 1, 2018.

Sukamdinata. Nana Syaodah, Metode Penelitian Pendidikan, Bandung: Remaja Rosdakarya, 2008.

Wijayanti. Winda dkk, Pengembangan Perangkat Blended Learning Berbasis Learning Management System pada Materi Listrik Dinamis, Jurnal ilmiah Pendidikan Fisika AL-BiRuNi, 06 (1), April 2017. 